\title{
COMMENT
}

\section{Government Transparency in Decision Making}

Sven Bluemmel, Victoria Information Commissioner, Australia

\begin{abstract}
Freedom of information (FOI) regimes are a hallmark of modern democracies and a crucial element of any government transparency and integrity framework. This paper examines how government responses to COVID-19 brought the need for greater transparency of government decision making to the fore. Genuine engagement with FOI regimes provides a fundamental mechanism to keep government decision makers accountable and increases and maintains trust capital between citizens and the state. In turn, governments rely on this trust capital to take strong and decisive action-as highlighted by global responses to COVID19. The author argues that FOI is an important mechanism to challenge poor government decision making, and ultimately enhance the long-term health of our democracy.
\end{abstract}

Keywords - Freedom of information, transparency, government decision making

Acknowledgments: The author thanks the Academy of the Social Sciences in Australia and Dominique Allen, Alysia Blackham, and Margaret Thornton, for the opportunity to partake in Melbourne Law School's 'Using Transparency to Achieve Equality' workshops throughout 2020, and to contribute to this special issue. The author acknowledges the contributions of colleagues Emily Arians, Cliff Bertram, Simone Martin and Adriana Nugent the preparation of this article.

Disclosure statement: No potential conflict of interest was reported by the authors.

License: This work is under Attribution-NonCommercial-ShareAlike 4.0 International (CC BY-NC-SA 4.0)

https://creativecommons.org/licenses/by-nc-sa/4.0/

Suggested citation: Bluemmel, S. (2021). “Government Transparency in Decision Making”, Law in Context, 37 (2): 119-124, DOI: https://doi.org/10.26826/law-in-context.v37i2.162

\section{Summary}

1. Introduction

2. Keeping government decisions makers accountable: FOI in action

3. Protecting rights and promoting equality through access to government information

4. Creating a culture of transparency

5. Measuring government success: a matter of trust

6. Conclusion

7. References

\section{INTRODUCTION}

Globally, the government response to COVID-19 has brought the need for sustained transparency in decision making to the fore. As identified by the Electronic Frontiers Foundation in a recent United States petition, '(a)s people are asked to make increasing sacrifices in their daily lives for the greater good of public health, the legitimacy of government decision-making requires a renewed commitment to transparency' (Kelley 2020). In 
Australia, we have seen the establishment of the Senate Select Committee on COVID-19 provide oversight and scrutiny of the federal government's response to COVID-19, in the wake of the parliamentary oversight regime established by our neighbours in New Zealand.

Alongside other avenues for parliamentary and government scrutiny, freedom of information (FOI) regimes are considered a hallmark of modern democracies and remain a crucial element of any government transparency and integrity framework. The introduction of FOI legislation represented a historical shift in Westminster-style governments (Stewart 2015), increasing transparency to the public and ultimately rebalancing the relationship between the citizen and the state.

Openness of information enhances government accountability and the long-term health of our democracy. More than ever, genuine engagement with FOI regimes provides a fundamental mechanism to scrutinise government decisions - increasing and maintaining trust capital between citizens and the state. In turn, governments rely on this trust capital to take strong and decisive action.

\section{KEEPING GOVERNMENT DECISION MAKERS AC- COUNTABLE: FOI IN ACTION}

The underlying principles of Australia's administrative law framework are open and accountable government (Ludwig 2010). FOI laws put both openness and accountability into practice, allowing citizens to access information held by government. FOI legislation provides transparency for government decision making primarily in two ways. First, by providing a general right of access to documents held by government, with some exceptions, and a corresponding duty on government decision makers to provide detailed reasons when access is denied. Second, the proactive publication of certain information by government agencies under FOI legislation provides transparency about their structure, functions, operations, policies and practices.

Proactive disclosure of government information, such as the publication of policy or other non-sensitive documents on an agency's website, can reduce the resourcing impact of responding to FOI requests and demonstrates a commitment to transparency. Proactive release of information held by government can complement other government efforts to increase transparency and accountability, including open data initiatives, as well as traditional transparency mechanisms, such as the media.

FOI legislation also provides for the informal release of information held by government. Informal release offers several benefits in addition to making information available to the public promptly and inexpensively. It can be a simpler and more efficient process than responding to a request under FOI legislation and provides agencies with flexibility in how they respond to requests for government information. The experience of my office has been that informal release can improve outcomes for the community, as intended by FOI legislation and parliament, and enable agencies to better focus their FOI resources.

Proactive disclosure, or informal release under FOI legislation, can demonstrate sound decision-making. Using these methods, governments can release information to the public that shows appropriate consultation and due consideration of stakeholder views (Waller et al. 2009). Further, the knowledge that documents may become public should, one would expect, improve the standard of advice from public servants to Ministers (NSW Ombudsman 2009, Stewart 2015); this can help to ensure that government decisions are ultimately made on the best available information and in a fair and equitable manner.

The effectiveness of FOI schemes in enhancing government transparency does somewhat depend on the genuine engagement with, and understanding of, FOI legislation by public officials. Complementary mechanisms such as staff training and guidance offered to agencies are necessary for the objects of FOI legislation to be realised in practice (Vadlamannati and Cooray 2017). The FOI Professional Standards, recently issued by my office to assist Victorian agencies to understand their functions under the FOI Act, are an example of such guidance. 
The political context in which FOI laws operate is also relevant. A pro-disclosure culture is essential to establishing an effective open government regime (Stewart 2015), as well as leadership within government to prioritise access to information and, where possible, to authorise making information available without the need for an FOI request. Multinational initiatives such as the Open Government Partnership, aimed at securing commitments from member governments (including the Australian Federal Government) to promote transparency, can assist in creating the necessary cultural shift within governments to value openness over secrecy.

\section{PROTECTING RIGHTS AND PROMOTING EQUAL- ITY THROUGH ACCESS TO GOVERNMENT INFOR- MATION}

Access to government information and human rights are inextricably linked, complementing freedom of expression, the right to take part in public life and the right to privacy, as well as extending social and economic rights (McDonagh 2013). The United Nations Human Rights Committee published a General Comment on Article 19 of the International Covenant on Civil and Political Rights, enshrining freedoms of opinion and expression. The General Comment confirmed that Article 19 encompasses a general right of access to information held by public bodies, and that State parties should enact a means by which individuals can access information, like FOI legislation (Human Rights Committee 2011).

Victoria's FOI legislation was enacted in 1982 and forms part of a framework of access, protection and oversight mechanisms to protect the information rights of Victorians, alongside the Privacy and Data Protection Act 2014, the Public Records Act 1973 and the Charter of Human Rights and Responsibilities Act 2006 (the Victorian Charter). FOI legislation, along with the enactment of the Victorian Charter and legislative protections for privacy, assist to provide citizens with legally enforceable rights. This helps to ensure that the government will treat the information of citizens lawfully, in accordance with their information rights.
Information can be described as the lifeblood of society (Martin 2017) and the access to information provided by FOI allows citizens to participate more meaningfully in society. FOI can facilitate a more participatory and open form of government (Snell and Tyson 2000), by providing access to information to inform public opinion and debate. As we have seen with the response to COVID-19, governments globally must make significant decisions that affect public health, civil liberties and societal prosperity-the public's right to access information about such decisions is vital.

\section{CREATING A CULTURE OF TRANSPARENCY}

FOI allows for public scrutiny of the government decision making process, providing an avenue for the public to examine and challenge these abilities. The establishment of the COVID-19 Hotel Quarantine Inquiry in Victoria is a further example of the importance of ensuring mechanisms for transparency and accountability for government decision making. Engagement with FOI can support the development of the necessary organisational culture to ensure accountability and transparency on an operational level within the public sector.

FOI can also be used as a tool to expose observed government corruption (Vadlamannati and Cooray 2017), bias on the part of the decision maker, or attempts to discriminate in the policy making process. While there is currently a lack of empirical data on the effectiveness of FOI both on an individual level (for example, increased democratic participation of citizens) and macro level (improved responsiveness of government intuitions), emerging theory suggests that FOI can create a space for ordinary citizens to better engage with government (Calland and Bentley 2013).

When considering the link between government transparency and trust in the context of FOI, there is one lingering notion that I would like to dispel - the long-held view of some that the operation of FOI potentially diminishes the ability of public servants to provide 'frank and fearless' advice to Ministers. This belief can be evident in tactics such as limited record-keeping of advice provided to government, in an attempt to evade disclosure under FOI (Waller et al. 2009), or taking an 
overly technical approach to the application of exemptions under FOI legislation. The view that FOI can limit the ability for government decision makers to thrash out ideas in the policy making process is based on a static approach to the objects of FOI legislation. On the contrary, transparency and accountability have long been fundamental values for public servants to uphold, demonstrated by a commitment to good record-keeping (Bartos 2020) and meaningful engagement with government transparency mechanisms, like FOI.

Views by government that disclosure of information will lead to ill-informed or unnecessary public debate of government policy also reflects a sentiment by the public sector, that considers the public playing a limited role in scrutinising the basis upon which a government decision has been made. At a time when multiple public inquiries and royal commissions have been established to seek to understand and examine complex issues in public, judgement as to what the public needs to know and should debate is an issue best left to the public to determine, not the public sector or government. While the exemptions in FOI legislation recognise that there will always be classes of government information excluded from public release, these need to be reconciled with public expectations of open and transparent governments (Snell and Tyson 2000).

In modern governments, positive engagement with FOI laws can be a marker of a productive and trusting relationship between the citizen and the State.

\section{MEASURING GOVERNMENT SUCCESS: A MATTER OF TRUST}

A sign of a competent government is a high level of trust in government and the public sector. Governments increasingly rely on this 'trust currency' to facilitate prompt and effective responses to public threats, make binding decisions and commit resources to achieve certain policy outcomes (Chanley, Rudolph and Rahn 2000). We have witnessed a particularly powerful illustration of this with the COVID-19 pandemic.

In times of crisis, governments need to provide sufficient information to citizens to demonstrate the basis for asking citizens to make sacrifices for the greater good, such as temporary restrictions on individual rights and freedoms. I consider that the skilful handling of a public crisis, based on a 'back to basics' approach of due accountability for government decision makers (Bartos, 2020), can temporarily raise trust levels in government.

The 'rally around the flag' effect (Mueller 1970) of citizens favouring unity over partisanship can increase trust in government to put ideological differences aside and take action (van Holm 2020). In some instances, this can lead to a temptation for the executive to overstep and weaken some established checks and balances in the name of rapid and strong response. This is particularly likely when governments introduce measures that may threaten the foundations of our democracy, such as the rule of law, or disproportionately impinge on individual liberties. This has certainly been observed in Australia in the context of metadata retention laws and other counterterrorism and national security measures (Triggs 2017).

A major study of the 2019 Federal Election conducted by the Australian National University (ANU) showed that trust in government is at an all-time low and satisfaction with democracy at its lowest level since the constitutional crisis of the 1970s, following the dismissal of Gough Whitlam as Prime Minister (Cameron and McAllister 2019). These results reflect the continuing rise of distrust in government and public institutions observed in most industrialised democracies (Dalton 2005). I hope that the public health emergency that COVID-19 has presented will provide the necessary 'shock to the system' for governments to prioritise sustainable ways to rebuild public trust in government and its institutions. Preserving the public's right to access government information is one way to do this.

The implementation of the Federal Government's contact tracing app to help contain the spread of COVID-19 within the community offers a good benchmark for the expected level of transparency and consultation required to gain the public trust necessary for effecting government initiatives (Burton 2020). The 
'transparency by design' approach of enshrining oversight measures for the data in legislation, as well as consulting on both the relevant legislation and design of the app, demonstrated a commitment to the responsible and proportionate use of citizens' personal information. While not the focus of this paper, increased public trust in government is not only a result of government motive, but also of perceived competence. A 2020 study of public trust in government during the COVID-19 pandemic found that increases in trust in organisations to maintain the privacy of personal information (during the response to COVID-19) appears to be linked to corresponding increases in confidence in the Federal Government, State and Territory Governments and the public service across Australia (Biddle et al. 2020).

Building public trust has been vital in the response to COVID-19 in Victoria - a state that in 2020, felt the weight of lockdown and compliance fatigue.

\section{CONCLUSION}

Observing government responses around the globe to COVID-19 has highlighted that the fundamental values of transparency and accountability in public servants has not changed (Bartos 2020). These values are enshrined in the FOI Act and the willingness of governments to engage with transparency mechanisms can increase trust in government-a continuing measure of government success.

Rejecting practices resulting in excessive secrecy can improve government decision making, allowing for more inclusive government initiatives and services, better aligned with community expectations. As we have observed in the comparatively successful management of COVID-19 of the New Zealand government, a good oversight and accountability framework for government action need not be an impediment to strong and decisive action. In fact, it can be an asset.

\section{REFERENCES}

1. Bartos, S. 2020. "If you're in the public service, the fundamentals will never, ever change." The Mandarin (online), 16 October.

https://www.themandarin.com.au/142585-ifyoure-in-the-public-service-the-fundamentalswill-never-ever-change/. Accessed 20/10/2020

2. Biddle, N., Edwards, B., Gray, M., Hiscox, M., McEachern, S. and Sollis, K. 2020. "Data trust and data privacy in the COVID- 19 period" ANU Centre for Social Research and Methods COVID-19 publications. https://csrm.cass.anu.edu.au/research/publications/data-trust-and-data-privacy-covid-19-period. Accessed 11/1/21

3. Burton, T. 2020. "App rewrites the rules for government services." The Financial Review (online), 21 May. https://www.afr.com/politics/federal/app-rewrites-the-rules-for-government-services-20200515-p54tdk Accessed $12 / 10 / 20$

4. Calland, R. and Bentley, K. 2013. "The Impact and Effectiveness of Transparency and Accountability Initiatives: Freedom of Information." Development Policy Review, 31(1): 69-77.

5. Cameron, S. and McAllister, I. 2019. The 2019 Australian Federal Election: Results from the Australian Election Study (December 2019). https://australianelectionstudy.org/wp-content/uploads/The-2019-Australian-FederalElection-Results-from-the-Australian-ElectionStudy.pdf. Accessed 12/10/20.

6. Chanley, V., Rudolph, T. and Rahn, W. 2000. "The Origins and Consequences of Public Trust in Government: A Time Series Analysis." The Public Opinion Quarterly, 64 (3): 239- 256.

7. Dalton, R. 2005. "The Social Transformation of Trust in Government." International Review of Sociology, 15(1): 133-154. 
8. Human Rights Committee, General Comments No 34 (2011): Freedom of opinion and expression (Article 19 of the International Covenant of Civil and Political Rights) UN CCPR/C, 102nd session, UN Doc CCPR/C/GC/34 (12 September 2011). https://www2.ohchr.org/english/bodies/hrc/docs/gc34.pdf

9. Kelley, J. 2020. "Governments Must Commit to Transparency During COVID-19 Crisis" Electronic Frontier Foundation, online, 20 March. https://www.eff.org/deeplinks/2020/03/governments-must-commit-transparency-duringcovid-19-crisis. Accessed 25/9/20.

10. Ludwig, J. 2010. "The Freedom of Information Act - No Longer a Substantial Disappointment." Administrative Review Council - Admin Review 59 (4). http://classic.austlii.edu.au/au/journals/AdminRw/2010/3.html.

Accessed 6/10/20.

11. Martin, W. 2017. The Global Information Society. Routledge, New York.

12. McDonagh, M. 2013. "The Right to Information in International Human Rights Law." Human Rights Law Review 13 (1): 25 - 55.

13. Mueller, J. 1970. "Presidential Popularity from Truman to Johnson." The American Political Science Review, 64 (1): 18 - 34.

14. NSW Ombudsman, 2009. Opening up government: Review of the Freedom of Information Act 1989 (Special Report to Parliament under s 31 of the Ombudsman Act 1974, February 2009), 57. http://www.austlii.edu.au/au/other/NSW OmbSRP/2009/1.pdf.

Accessed 12/10/2020

15. OVIC. 2020. "The State of Freedom of Information in Victoria: Five years in review 2014 2019." https://ovic.vic.gov.au/state-of-freedom-of-information-in-victoria/informationcommissioners-foreword/.

Accessed 10/10/20

16. Snell, R. and Tyson, N. 2000. "Back to the Drawing Board: Preliminary Musings on Redesigning
Australian Freedom of Information." 85 Freedom of Information Review 85: 2-6.

https://papers.ssrn.com/sol3/papers.cfm?abstract $\mathrm{id}=2540685$ Accessed 6/10/20

17. Stewart, D. 2015. "Assessing Access to Information in Australia: The impact of freedom of information laws on the scrutiny and operation of the Commonwealth government." In Wanna, J., Lindquist, E. A. and Marshall, P. (eds.) New Accountabilities, New Challenges. ANU Press, Acton, Australia.

https://press-files.anu.edu.au/downloads/press/p314521/pdf/book.pdf\#page=93 Accessed 7/10/20.

18. Triggs, G. 2017. "Overreach of Executive and Ministerial Discretion: A Threat to Australian Democracy." Victoria University Law and Justice Journal 71 (1).

http://classic.austlii.edu.au/au/journals/VicULawJJl/2017/3.html Accessed 12/10/20.

19. Vadlamannati, K. and Cooray, A. 2017. "Transparency Pays? Evaluating the Effects of the Freedom of Information Laws on Perceived Government Corruption." Journal of Developmental Studies, 53 (1): 116 - 137.

20. van Holm, E. 2020. The Role of Partisanship, Circumstances, and Action on Citizen Views of Government Effectiveness during the Initial COVID19 Response (May 7, 2020).

https://papers.ssrn.com/sol3/papers.cfm?abstract id=3594967 Accessed 12/10/20

21. Waller, P., Morris, R.M., Simpson, D. and Hazell, R. 2009. "Understanding the Formulation and Development of Government Policy in the context of FOI." Report prepared for the Information Commissioner's Office by The Constitution Unit, University College London. https://www.ucl.ac.uk/constitutionunit/sites/constitution-unit/files/ICO FOI and Policy.pdf Accessed 6/10/20 